\title{
Targeting Angiogenesis Using a C-Type Atrial Natriuretic Factor-Conjugated Nanoprobe and PET
}

\author{
Yongjian Liu ${ }^{1}$, Eric D. Pressly², Dana R. Abendschein ${ }^{3}$, Craig J. Hawker ${ }^{2}$, Geoffrey E. Woodard ${ }^{4}$, \\ Pamela K. Woodard ${ }^{* 1}$, and Michael J. Welch*1 \\ ${ }^{1}$ Department of Radiology, Washington University, St. Louis, Missouri; ${ }^{2}$ Department of Materials, Chemistry, and Biochemistry, \\ University of California, Santa Barbara, California; ${ }^{3}$ Department of Internal Medicine, Washington University, St. Louis, Missouri; \\ and ${ }^{4}$ Department of Medicine, Uniformed Services University of the Health Sciences, Bethesda, Maryland
}

Sensitive, specific, and noninvasive detection of angiogenesis would be helpful in discovering new strategies for the treatment of cardiovascular diseases. Recently, we reported the ${ }^{64} \mathrm{Cu}$ labeled C-type atrial natriuretic factor (CANF) fragment for detecting the upregulation of natriuretic peptide clearance receptor (NPR-C) with PET on atherosclerosis-like lesions in an animal model. However, it is unknown whether NPR-C is present and overexpressed during angiogenesis. The goal of this study was to develop a novel CANF-integrated nanoprobe to prove the presence of NPR-C and offer sensitive detection with PET during development of angiogenesis in mouse hind limb. Methods: We prepared a multifunctional, core-shell nanoparticle consisting of DOTA chelators attached to a poly(methyl methacrylate) core and CANF-targeting moieties attached to poly(ethylene glycol) chain ends in the shell of the nanoparticle. Labeling of this nanoparticle with ${ }^{64} \mathrm{Cu}$ yielded a high-specific-activity nanoprobe for PET imaging NPR-C receptor in a mouse model of hind limb ischemia-induced angiogenesis. Histology and immunohistochemistry were performed to assess angiogenesis development and NPR-C localization. Results: ${ }^{15} \mathrm{O}-\mathrm{H}_{2} \mathrm{O}$ imaging showed blood flow restoration in the previously ischemic hind limb, consistent with the development of angiogenesis. The targeted DOTA-CANF-comb nanoprobe showed optimized pharmacokinetics and biodistribution. PET imaging demonstrated significantly higher tracer accumulation for the targeted DOTA-CANFcomb nanoprobe than for either the CANF peptide tracer or the nontargeted control nanoprobe ( $P<0.05$, both). Immunohistochemistry confirmed NPR-C upregulation in the angiogenic lesion with colocalization in both endothelial and smooth muscle cells. PET and immunohistochemistry competitive receptor blocking verified the specificity of the targeted nanoprobe to NPR-C receptor. Conclusion: As evidence of its translational potential, this customized DOTA-CANF-comb nanoprobe demonstrated superiority over the CANF peptide alone for imaging NPR-C receptor in angiogenesis.

Received Feb. 21, 2011; revision accepted Jun. 27, 2011.

For correspondence or reprints contact: Michael J. Welch, Department of Radiology, Washington University, Campus Box 8225, 510 S. Kingshighway Blvd., St. Louis, MO 63110.

E-mail: welchm@mir.wustl.edu

${ }^{*}$ Contributed equally to this work.

Published online Nov. 2, 2011.

COPYRIGHT ๑ 2011 by the Society of Nuclear Medicine, Inc.
Key Words: angiogenesis; natriuretic peptide clearance receptor; positron emission tomography; nanoparticle; molecular imaging

J Nucl Med 2011; 52:1956-1963

DOI: 10.2967/jnumed.111.089581

A ngiogenesis is a complex biologic process that plays a critical role in many human diseases such as atherosclerosis, peripheral arterial disease, and cancer (1). During the formation of new capillaries, various cell interactions produce an array of biologic targets for developing angiogenesis diagnostic agents and for assessing the efficacy of antiangiogenic therapy such as vascular endothelial growth factor $(2,3)$ and vascular integrin $\alpha_{v} \beta_{3}(4,5)$. Because the current focus of cardiovascular medicine is on early, sensitive, and specific detection and prevention of disease at the molecular level, noninvasive targeted radiotracer-based imaging modalities, especially PET, are highly appealing in terms of potential clinical translation $(6,7)$. With the development of new synthetic strategies in nanotechnology, PET using well-defined nanostructures has increased significantly because of the inherent advantages offered by these materials, such as a substantial loading capacity to increase diagnostic sensitivity and targeting efficiency, multifunctionality to permit multimodality imaging, and versatility in structure to tailor the in vivo pharmacokinetics for improved targeting $(8,9)$.

The principal stimuli for cardiovascular angiogenesis include tissue ischemia and hypoxia, which involve a cascade of events and offer new biologic targets that hold promise for novel cardiovascular medicine. Natriuretic peptides are a family of heart- and vessel-derived hormones that play an important role in cardiovascular homeostasis by interacting with their corresponding natriuretic peptide receptors (NPRs) (10). Among the 4 natriuretic peptide family members, atrial natriuretic peptide and C-type natriuretic peptide have been demonstrated to suppress signaling of vascular endothelial growth factor and to attenuate angiogenesis (11-13) and have been widely investigated for their therapeutic potential $(14,15)$. Among the NPRs, 
the clearance receptor (NPR-C), representing approximately $95 \%$ of the NPR population, is the only NPR that recognizes all natriuretic peptides and natriuretic peptide fragments (16). These features make NPR-C an ideal target for imaging the antiangiogenic effect of natriuretic peptides. However, the presence of NPR-C during angiogenesis has not been assessed yet.

We previously reported that the small-molecule ${ }^{64} \mathrm{Cu}-$ labeled DOTA-C-type atrial natriuretic factor (CANF) conjugate was a promising candidate tracer for PET of NPR-C in a rabbit atherosclerosis model (17) and that an amphophilic comblike nanoparticle had been developed as a robust and modular platform for in vivo targeting (18). In the current study, we prepared multifunctional CANF-conjugated comblike nanoprobes and compared their performance to that of the CANF peptide tracer alone and the nontargeted control comb nanoprobe without CANF conjugation, for PET imaging of NPR-C receptors in a mouse model of hind limb ischemia (HLI) (4). The targeted imaging and superiority of the DOTA-CANF-comb nanoprobe for upregulated NPR-C during angiogenesis were confirmed with the use of small-animal PET/CT.

\section{MATERIALS AND METHODS}

Materials were purchased from Sigma-Aldrich and used without further purification unless otherwise stated. The ${ }^{64} \mathrm{Cu}$ (half-life $=12.7 \mathrm{~h}, \beta^{+}=17 \%, \beta^{-}=40 \%$ ) and ${ }^{15} \mathrm{O}-\mathrm{H}_{2} \mathrm{O}$ (halflife $=2.07 \mathrm{~min}, \beta^{+}=99.9 \%$ ) were produced at the Washington University cyclotron facility $(19,20)$. Functionalized poly(ethylene glycol) (PEG) derivatives were obtained from Intezyne Technologies. Tris-t-butylester-DOTA, 1,4,7,10-tetraazacyclododecane, and DOTA- $N$-hydroxysuccinimide ester were purchased from Macrocyclics. CANF (rat atrial natriuretic factor (4-23), des-Gln ${ }^{18}$, des$\mathrm{Ser}^{19}$, des-Gly ${ }^{20,22}$, des-Leu ${ }^{21}$ ) was purchased from Tianma Pharma. Centricon tubes were purchased from Millipore. HiTrap desalting columns were from GE Healthcare Biosciences. Zeba desalting spin columns were from Pierce. Dithiol ester reversible addition-fragmentation chain transfer agent, DOTA methacrylate, $\mathrm{N}$-succinimidyl 4-pentynoate, and DOTA-CANF were prepared as previously reported $(17,18,21-23)$.

Polymeric materials were characterized by ${ }^{1} \mathrm{H}$ and ${ }^{13} \mathrm{C}$ nuclear magnetic resonance spectroscopy using either a $200-$ or $500-\mathrm{MHz}$ spectrometer (Bruker) with the residual solvent signal as an internal reference. Gel permeation chromatography was performed in dimethylformamide on a Waters system equipped with four $5-\mu \mathrm{m}$ columns $(300 \times 7.7 \mathrm{~mm}$; Waters $)$ connected in series with increasing pore size $\left(10,10^{2}, 10^{3}\right.$, and $\left.10^{4} \mathrm{~nm}\right)$ and 410 differential refractometer index and 996 photodiode array detectors (Waters). The molecular weights of the polymers were calculated relative to linear poly(methyl methacrylate) or PEG standards. Infrared spectra were recorded on a Spectrum 100 with a Universal ATR sampling accessory (Perkin Elmer). Fast protein liquid chromatography was performed on an ÄKTA system (GE Healthcare) equipped with ultraviolet and 170 radioactivity detectors (Beckman) on a Superose 12 10/300 GL size-exclusion column $(10 \times 300 \mathrm{~mm}, \mathrm{GE}$ Healthcare). An isocratic elution was performed at $0.8 \mathrm{~mL} / \mathrm{min}$ using a mixture of $20 \mathrm{mM}$ 4-(2-hydroxyethyl)-1-piperazineethanesulfonic acid and $150 \mathrm{mM} \mathrm{NaCl}$ with neutral $\mathrm{pH}$.

\section{Synthesis of Acetylene-CANF}

CANF (59.3 mg, $0.037 \mathrm{mmol}$ ) was dissolved in $2 \mathrm{~mL}$ of anhydrous dimethylformamide, and 4-pentynoic anhydride(19.2 mg, $0.098 \mathrm{mmol}$ ) dissolved in $1.5 \mathrm{~mL}$ of anhydrous dimethylformamide was added dropwise to the solution and allowed to stir for $2 \mathrm{~d}$. Cold diethyl ether $(15 \mathrm{~mL})$ was added to the solution to triturate the product, which was subsequently dissolved in $2 \mathrm{~mL}$ of MilliQ water (Millipore) and freeze-dried (yield, $47.0 \mathrm{mg} ; 75 \%$ ); $\mathrm{M}_{\mathrm{w}}$ (electrospray ionization), 1,674.73 $\{\mathrm{M}+\mathrm{H}]^{+}$(calculated, 1,674.80).

\section{Synthesis of PEG CANF Methacrylate}

$\mathrm{N}_{3}$-PEG methacrylate $(75.4 \mathrm{mg}, 0.015 \mathrm{mmol})$ and acetyleneCANF (42.8 mg, $0.025 \mathrm{mmol}$ ) were dissolved in a solution of $1.0 \mathrm{~g}$ dimethyl sulfoxide and $0.65 \mathrm{~g}$ MilliQ water followed by the addition of $50 \mu \mathrm{L}$ of $5 \%$ (weight percent) aqueous copper sulfate $(0.018 \mathrm{mmol})$ and $75 \mu \mathrm{L}$ of $5 \%$ (weight percent) aqueous sodium ascorbate $(0.016 \mathrm{mmol})$, respectively. The reaction was allowed to stir for $2 \mathrm{~d}$ with repeated additions of $\mathrm{CuSO}_{4}(50 \mu \mathrm{L})$ and sodium ascorbate $(75 \mu \mathrm{L})$ solutions after $1 \mathrm{~d}$. The product was purified by washing $(10 \times)$ with MilliQ water in $15-\mathrm{mL}$ Centricon tubes (YM5; Millipore) and freeze-dried (yield, $48 \mathrm{mg} ; 41 \%$ ); Fourier transform infrared, wave number $\left(\mathrm{cm}^{-1}\right)$ : 3,315, 2,881, 1,655, 1,466, 1,342, 1,099, 962, 841; gel permeation chromatography number average molecular weight, $6.5 \mathrm{kDa}$; polydispersity index, 1.1 (poly (methyl methacrylate) standards, dimethylformamide).

\section{Synthesis of DOTA-CANF-Comb}

The DOTA-CANF-comb and nontargeted DOTA-comb were synthesized as previously reported (23), replacing the RGD-PEG methacrylate with CANF-PEG methacrylate; number average molecular weight, $205 \mathrm{kDa}$, and polydispersity index, 1.20 , for DOTA-CANF-comb; number average molecular weight, $220 \mathrm{kDa}$, and polydispersity index, 1.25, for control DOTA-comb (gel permeation chromatography poly(methyl methacrylate) standards, dimethylformamide).

\section{Assembly of Nanoparticles}

After removal of t-butyl protecting groups (18), the polymers were dissolved in dimethyl sulfoxide ( $1 \%$ [weight percent]), a rapid addition of an equal aliquot achieved assembly, and dimethyl sulfoxide was removed by centrifugal filtration, resulting in particles of 22.0 and $20.4 \mathrm{~nm}$ (dynamic light scattering) for the targeting DOTA-CANF-comb particles ( $\zeta$-potential, $-1.1 \pm 2 \mathrm{mV}$ ) and nontargeting DOTA-comb particles ( $\zeta$-potential, $-35 \pm 2 \mathrm{mV}$ ), respectively (Supplemental Fig. 1; supplemental materials are available online only at http://jnm.snmjournals.org).

\section{The Murine HLI Model}

All animal studies were performed in compliance with guidelines set forth by the National Institutes of Health Office of Laboratory Animal Welfare and approved by the Washington University Animal Studies Committee. Angiogenesis was induced in male C57BL/6 mice by placing 2 ligatures separated by $0.5 \mathrm{~cm}$ on a femoral artery above the saphenous branch, followed by excision of the intervening segments. As a sham control, the contralateral femoral artery was exposed but not ligated or excised. The double ligation and vascular resection of a femoral arterial segment produced severe HLI as verified by Doppler blood flow measurements (Perimed) in the distal thigh muscle and a significant increase in muscle blood flow (quantified as the ratio of ischemic to nonischemic hind limb flow) after $7 \mathrm{~d}$, consistent with lack of 
restoration of flow to the presurgery level and flow enhancement induced by angiogenesis (4). Only animals showing this pattern of a profound decrease in distal muscle blood flow at day 0 followed by a marked increase in muscle blood flow at day 7 were used in this study. Approximately $70 \%$ of mice undergoing HLI surgery showed the required pattern.

\section{${ }^{15}$ O-Water PET Estimation of Blood Flow Change}

To measure the blood flow changes caused by the surgical HLI and the resulting angiogenesis, about $22-37 \mathrm{MBq}$ of ${ }^{15} \mathrm{O}$-water were intravenously injected into the same mice $(n=4)$ after HLI surgery (day 0) and again 7 d later (day 7) (24). A 0- to 5-min dynamic scan was immediately obtained after the intravenous injection of ${ }^{15} \mathrm{O}-\mathrm{H}_{2} \mathrm{O}$ on an Inveon PET/CT system (Siemens Medical Solution). The relative blood flow change was evaluated by standardized uptake values (SUVs) (25).

\section{${ }^{64} \mathrm{Cu}$ Labeling of DOTA-CANF, DOTA-CANF-Comb, and DOTA-Comb}

${ }^{64} \mathrm{Cu}$ (half-life $=12.7 \mathrm{~h}, \beta^{+}=17 \%, \beta^{-}=40 \%$ ) was produced on the Washington University Medical School CS-15 cyclotron by the ${ }^{64} \mathrm{Ni}(\mathrm{p}, \mathrm{n}){ }^{64} \mathrm{Cu}$ nuclear reaction at a specific activity of $1.85-$ $7.40 \mathrm{GBq} / \mu \mathrm{g}$ at the end of bombardment (19). DOTA-CANFcomb and control DOTA-comb (5 $\mu \mathrm{g}$, about $6 \mathrm{pmol})$ were labeled with $185 \mathrm{MBq}$ of ${ }^{64} \mathrm{Cu}$ in $200 \mu \mathrm{L}$ of $0.1 \mathrm{M}, \mathrm{pH} 5.5$, ammonium acetate buffer at $80^{\circ} \mathrm{C}$ for $1 \mathrm{~h}$ with a yield of $60.5 \% \pm 7.3 \%(n=$ 15). The ${ }^{64} \mathrm{Cu}$-DOTA-CANF-comb and ${ }^{64} \mathrm{Cu}-\mathrm{DOTA}-\mathrm{comb}$ were purified by $2 \mathrm{~mL}$ of Zeba spin desalting column after ethylene diamine tetraacetic acid challenge $(10 \mathrm{mM}$ in $50 \mathrm{mM}, \mathrm{pH} 7.4$, phosphate buffer). The radiochemical purity of the labeled nanoprobe was measured by radioactive thin-layer chromatography (Bioscan).

\section{Biodistribution Studies}

${ }^{64} \mathrm{Cu}$-DOTA-CANF, ${ }^{64} \mathrm{Cu}$-DOTA-CANF-comb, and ${ }^{64} \mathrm{Cu}-$ DOTA-comb were reconstituted in $0.9 \%$ sodium chloride (APP Pharmaceuticals) for intravenous injection. Male C57BL/6 mice weighing 20-25 g ( $n=4)$ were anesthetized with inhaled isoflurane, and about $370 \mathrm{kBq}$ of labeled nanoparticles $(0.8-1.2 \mu \mathrm{g} / \mathrm{kg}$ of body weight) or DOTA-CANF peptide $(0.8-1.1 \mu \mathrm{g} / \mathrm{kg}$ of body weight) in $100 \mu \mathrm{L}$ of saline were injected via the tail vein. The mice were reanesthetized before they were euthanized by cervical dislocation at each time point (1, 4, and $24 \mathrm{~h}$ ) after injection. Organs of interest were collected, weighed, and counted in a well $\gamma$-counter (Beckman 8000). Standards were prepared and measured along with the samples to calculate the percentage injected dose (\%ID) per gram of tissue (26).

\section{PET/CT}

Mice showing an increase in blood flow above baseline level $7 \mathrm{~d}$ after HLI surgery $(n=6,8$, and 7 for DOTA-CANF, targeted DOTA-CANF-comb nanoprobe, and nontargeted comb, respectively) were anesthetized with isoflurane and injected intravenously with $3.7 \mathrm{MBq}$ of activity per $100 \mu \mathrm{L}$ via the tail vein (8-11 $\mu \mathrm{g} / \mathrm{kg}$ and $8-12 \mu \mathrm{g} / \mathrm{kg}$ of mouse body weight for the peptide and nanoprobes, respectively; the molar ratio of ${ }^{64} \mathrm{Cu}$-DOTACANF-comb to ${ }^{64} \mathrm{Cu}-\mathrm{DOTA}-\mathrm{CANF}$ injected was 1:100). For ${ }^{64} \mathrm{Cu}$-DOTA-CANF, a 0- to 60-min dynamic scan was obtained on the microPET Focus 120/220 (Siemens Medical Solutions) and microCAT II (Siemens Medical Solutions) scanners. The smallanimal PET images (corrected for attenuation, scatter, normalization, and camera dead time) and small-animal CT images were coregistered with fiducial markers attached to the animal bed and
AMIRA (Mercury Computer Systems). For ${ }^{64} \mathrm{Cu}-\mathrm{DOTA}-\mathrm{CANF}-$ comb and ${ }^{64} \mathrm{Cu}$-DOTA-comb nanoprobes, the imaging sessions were performed on the Inveon PET/CT system and the microPET Focus 220 at $1 \mathrm{~h}, 4 \mathrm{~h}$ (one 30-min frame, both), and $24 \mathrm{~h}$ after injection (one 60-min frame). All PET scanners were crosscalibrated periodically. All image analysis was performed with ASIPro (4). The tracer SUVs were not corrected for partial-volume effects (17).

After undergoing PET, the animals were euthanized by exsanguination and the thighs containing the previously ischemic and nonischemic control muscles were perfusion-fixed in situ with freshly prepared Michel transport medium (American MasterTech Scientific Inc.) for histopathology and immunohistochemistry.

\section{Competitive Receptor Blocking Studies}

Competitive receptor blocking studies were performed on mice with HLI surgery $(27 \pm 2.5 \mathrm{~g})$ for ${ }^{64} \mathrm{Cu}$-DOTA-CANF by coinjection of unlabeled CANF peptide (a 100:1 molar ratio of CANF: ${ }^{64} \mathrm{Cu}$-DOTA-CANF, $n=4$ ) on day 7 after the surgery immediately followed by 0 - to 60 -min dynamic scans. For the ${ }^{64} \mathrm{Cu}-$ DOTA-CANF-comb, 8 HLI mice $(28 \pm 3.1 \mathrm{~g})$ received coinjection of unlabeled DOTA-CANF-comb nanoparticle and ${ }^{64} \mathrm{Cu}$-DOTACANF-comb in a 500:1 molar ratio on day 7 after the surgery and were scanned with PET/CT at 1, 4, and $24 \mathrm{~h}$ after injection.

\section{Histopathology and Immunohistochemistry}

The perfusion-fixed tissue was stored overnight at $4{ }^{\circ} \mathrm{C}$ in the Michel transport medium before being frozen in optimal-cuttingtemperature compound and step-sectioned $(7 \mu \mathrm{m})$ at $100-\mu \mathrm{m}$ intervals on a cryostat. Some of the sections at each step were stained with hematoxylin and eosin for identification of the morphology of the tissue.

Tissue sections at $100-\mu \mathrm{m}$ intervals were also prepared for double immunofluorescent staining of NPR-C and either platelet endothelial cell adhesion molecule (PECAM-1) for endothelial cells or $\alpha$-actin for vascular smooth muscle cells. The method for double immunolabeling followed the manufacturer's recommendations (Vector Laboratories). Briefly, the steps included avidin/biotin blocking; protein blocking with 5\% normal horse serum for the first antibody (mouse-derived endothelial cell 13.3 against CD31 [PECAM-1] or monoclonal antiactin isotype IgG2a) and $5 \%$ normal goat serum for the second antibody (anti-natriuretic peptide receptor $\mathrm{C}$ antibody [N-term] purified rabbit monoclonal); incubation for $30 \mathrm{~min}$ with the primary antibody diluted to 0.04 $0.5 \mathrm{mg} / \mathrm{mL}$ in buffer with normal serum added; incubation for $30 \mathrm{~min}$ with the biotinylated secondary antibody diluted to $15 \mu \mathrm{g} /$ $\mathrm{mL}$ in buffer with normal serum added; and incubation for $10 \mathrm{~min}$ with fluorescein avidin D cell-sorting grade (fluorescein isothiocyanate, $10 \mu \mathrm{g} / \mathrm{mL}$ in buffer) for the first antibody (PECAM-1 or $\alpha$-actin) and Texas Red (Molecular Probes Inc.) avidin D cell-sorting grade (rhodamine, $10 \mu \mathrm{g} / \mathrm{mL}$ in buffer) for the second antibody (NPR-C). Primary antibody binding to NPR-C was blocked by preincubation of diluted antibody with the cognate peptide $(0.5 \mathrm{mg} / \mathrm{mL})$ overnight at $4^{\circ} \mathrm{C}$ before immunohistochemistry staining. After a coverslip was placed, the slides were observed under the fluorescence microscope (Carl Zeiss) with appropriate filters.

\section{Statistical Analysis}

Group variation is described as mean \pm SD. Groups were compared using 1-way ANOVA with a Bonferroni posttest. Individual group differences were determined with use of a 2-tailed Mann-Whitney test. The significance level in all tests was $P \leq$ 
0.05. Prism, version 5.02 (GraphPad), was used for all statistical analyses.

\section{RESULTS}

\section{0-Water PET Determining Relative Blood Flow}

PET using ${ }^{15} \mathrm{O}$-water offers direct physiologic measurement of circulatory parameters for regional blood and vascular volume. After the induction of HLI, blood flow was immediately decreased (Supplemental Fig. 2A), consistent with the previous report (27). Quantitative dynamic SUVs of the nonischemic and ischemic limbs reached stability at the end of the scan and averaged $0.68 \pm 0.09$ and $0.15 \pm$ 0.04 (Supplemental Fig. 2B, $n=4$, both), respectively, yielding an ischemic-to-nonischemic SUV ratio of $0.22 \pm$ $0.06(n=4)$. On day 7 after HLI surgery, the repeated ${ }^{15} \mathrm{O}-$ water PET image showed the return of blood flow (Supplemental Fig. 2C) and the ischemic-to-nonischemic SUV ratio was increased to $0.83 \pm 0.06$ (Supplemental Fig. $2 \mathrm{D}, n=4$, $P<0.05$ ), consistent with an angiogenesis-induced increase of blood flow in the previously ischemic tissue.

\section{Biodistribution of DOTA-CANF, DOTA-CANF-Comb, and DOTA-Comb}

Biodistribution data showed a fast clearance profile of ${ }^{64} \mathrm{Cu}$-DOTA-CANF primarily through the kidneys, with minor accumulation in the liver and lungs and negligible uptake in other organs (Fig. 1A). At $1 \mathrm{~h}$ after injection, the blood retention of ${ }^{64} \mathrm{Cu}$-DOTA-CANF was only $0.92 \pm 0.45 \% \mathrm{ID} / \mathrm{g}$, whereas kidney retention was $13.7 \pm 2.06 \% \mathrm{ID} / \mathrm{g}$ (Fig. 1A). Liver uptake was constant over $24 \mathrm{~h}$, at less than $8 \% \mathrm{ID} / \mathrm{g}$.

The nontargeted ${ }^{64} \mathrm{Cu}$-DOTA-comb displayed higher blood retention and slower clearance $(25.4 \pm 3.04 \% \mathrm{ID} / \mathrm{g}$ at $1 \mathrm{~h}$ after injection, $P<0.001, n=4$ ) (Fig. 1B) than did ${ }^{64} \mathrm{Cu}$-DOTA-CANF. However, liver uptake was dominant during the 24-h study, with more than $40 \% \mathrm{ID} / \mathrm{g}$ at $1 \mathrm{~h}$ after injection, and peaked at $4 \mathrm{~h}$ after injection at $52.4 \pm 6.85$ $\% \mathrm{ID} / \mathrm{g}$. Spleen accumulation showed a similar pattern to liver accumulation, with a maximum of $27.8 \pm 6.52 \% \mathrm{ID} / \mathrm{g}$ at $4 \mathrm{~h}$ after injection. However, kidney uptake of the nontargeted ${ }^{64} \mathrm{Cu}$-DOTA-comb was similar to that of the ${ }^{64} \mathrm{Cu}$ DOTA-CANF tracer during the study.

The targeted ${ }^{64} \mathrm{Cu}$-DOTA-CANF-comb showed a superior biodistribution profile, with significantly improved circulatory retention (blood, lung, and heart) and reduced liver and renal clearance (Fig. 1C). Among the organs, the highest uptake was observed in blood, with $56.4 \pm 7.54 \% \mathrm{ID} / \mathrm{g}$, $48.2 \pm 2.31 \% \mathrm{ID} / \mathrm{g}$, and $23.8 \pm 2.40 \% \mathrm{ID} / \mathrm{g}$ at 1,4 , and $24 \mathrm{~h}$ after injection $(n=4$ for all). All were significantly higher $(P<0.001, n=4)$ than for either the control DOTAcomb or the CANF peptide tracer alone. In contrast, liver and spleen accumulations were significantly reduced $(P<0.001$, $n=4)$ to less than $10 \% \mathrm{ID} / \mathrm{g}$ during the 24 -h study when compared with the control DOTA-comb nanoprobe.

\section{PET/CT}

PET/CT with ${ }^{64} \mathrm{Cu}$-DOTA-CANF at $7 \mathrm{~d}$ after HLI surgery clearly showed tracer uptake in the distal thigh muscle,

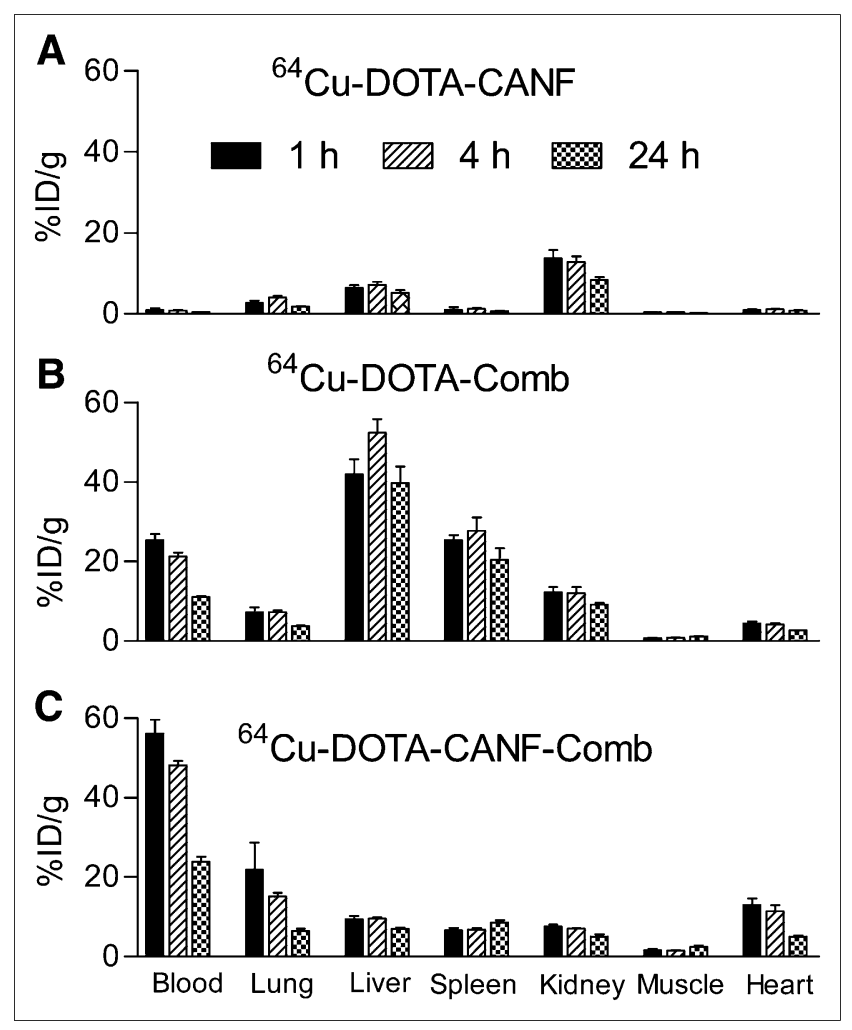

FIGURE 1. Biodistribution of ${ }^{64} \mathrm{Cu}$-DOTA-CANF, ${ }^{64} \mathrm{Cu}$-DOTAcomb, and ${ }^{64} \mathrm{Cu}-\mathrm{DOTA}-\mathrm{CANF}-\mathrm{comb}$ in C57BL/6 mice $(n=3-4 /$ group). (A) ${ }^{64} \mathrm{Cu}-\mathrm{DOTA}-\mathrm{CANF}$ showing fast renal clearance and low blood retention. (B) Nontargeted ${ }^{64} \mathrm{Cu}$-DOTA-comb nanoparticle showing improved blood retention but high liver and spleen uptake. (C) ${ }^{64} \mathrm{Cu}$-DOTA-CANF-comb nanoprobe showing superior pharmacokinetics relative to both CANF peptide tracer alone and nontargeted control nanoprobe

where ischemia had been induced previously, with weak signal deposited in the control, nonischemic limb (Fig. 2A). The uptake of ${ }^{64} \mathrm{Cu}$-DOTA-CANF in the previously ischemic limb was $1.85 \pm 0.19 \% \mathrm{ID} / \mathrm{g}(n=6)$; significantly higher $(P<0.001)$ than that obtained in the nonischemic control limb $(0.77 \pm 0.03 \% \mathrm{ID} / \mathrm{g}, n=6$, Fig. 2B). With competitive receptor blocking, the tracer uptake of the ischemic limb was reduced to a level similar to that acquired in the nonischemic limb (Figs. 2B and 2C), significantly lower $(P<0.001, n=4)$ than the uptake before blocking. The ischemic-to-nonischemic uptake ratio was also decreased from $2.34 \pm 0.40(n=6)$ to $1.24 \pm 0.26(n=4, P<$ 0.001) after blocking (Fig. 2D).

With targeted ${ }^{64} \mathrm{Cu}$-DOTA-CANF-comb nanoprobe, an increased accumulation at the lesion site of the ischemic limb was observed (Fig. 3A). The uptake was $6.30 \pm 1.07$ $\% \mathrm{ID} / \mathrm{g}(n=8) 1 \mathrm{~h}$ after injection, significantly higher $(P<$ $0.001)$ than that obtained $(1.40 \pm 0.52 \% \mathrm{ID} / \mathrm{g}, n=8)$ in the contralateral nonischemic limb (Figs. 3A and 3C) and, more importantly, higher $(P<0.001)$ than either the nontargeted ${ }^{64} \mathrm{Cu}$-DOTA-comb (Figs. 3B and 3C) or the ${ }^{64} \mathrm{Cu}$-DOTACANF tracer (Figs. 2A and 2B). During the 24-h study, the uptake of ${ }^{64} \mathrm{Cu}$-DOTA-CANF-comb in the ischemic limb 




FIGURE 2. PET/CT image of ${ }^{64} \mathrm{Cu}$-DOTA-CANF in HLI-induced angiogenesis model. (A) Coronal slice showing accumulation of ${ }^{64} \mathrm{Cu}$-DOTA-CANF tracer at injured limb on day 7. (B) Uptake of ${ }^{64} \mathrm{Cu}$-DOTA-CANF at ischemic $(n=6)$ and nonischemic $(n=6)$ limbs, as well as blocking study $(n=4)$. (C) Significant reduction of uptake upon competitive receptor blocking with coadministration of unlabeled CANF peptide. (D) Ischemic-to-nonischemic uptake ratios of nonblocking and blocking studies ( $n=4$, both).

gradually increased to $8.50 \pm 1.38 \% \mathrm{ID} / \mathrm{g}$, in contrast to the constant SUV obtained in the contralateral nonischemic limb (Fig. 3C). Moreover, when the ischemic-to-nonischemic uptake ratios were compared, the targeted ${ }^{64} \mathrm{Cu}$-DOTACANF-comb showed significantly higher $(P<0.001, n=$ 8) ratios of $4.35 \pm 0.87$ at $1 \mathrm{~h}$ after injection and $5.35 \pm 0.68$ at $24 \mathrm{~h}$ after injection than those obtained with either control ${ }^{64} \mathrm{Cu}$-DOTA-comb probe (Fig. 3D) or ${ }^{64} \mathrm{Cu}$-DOTA-CANF (Fig. 2D).

\section{Histopathology and Immunohistochemistry}

Thigh muscle from the previously ischemic hind limb showed areas of coagulation necrosis but also an abundance of new capillaries, which in some sections appeared as tightly packed bundles identified by PECAM- 1 staining of endothelial cells and by hematoxylin and eosin staining (28). Moreover, double immunostaining for PECAM-1 (Supplemental Fig. 3A) and NPR-C (Supplemental Fig. 3C) showed colocalization of NPR-C and PECAM-1 on the endothelium of neovessels (Figs. 4A and 4E). The increased density of neovessels reflecting angiogenesis in previously ischemic hind limbs was not observed in the tissue from the sham- operated, nonischemic limb. Little NPR-C staining was observed in the tissue from the sham-operated limb, suggesting the presence of NPR-C primarily on the endothelium of neovessels rather than established capillaries (Figs. 4B and 4F). Vascular smooth muscle cells identified with an antibody to $\alpha$-actin also exhibited staining for NPR-C (Figs. 4C and $4 \mathrm{G}$ ). Interestingly, both neovessels in the previously ischemic limb and existing capillaries in the nonischemic limb showed colocalization of NPR-C and $\alpha$-actin-unlike the selectivity shown for the endothelium of neovessels, although there was more fluorescent signal from the ischemic tissue.

\section{Competitive Receptor Blocking}

Competitive receptor blocking with coinjection of unlabeled DOTA-CANF resulted in a significant uptake decrease in the ischemic region (Figs. 2C and 2D). Quantitative uptake of ${ }^{64} \mathrm{Cu}$-DOTA-CANF-comb in the lesion site $7 \mathrm{~d}$ after the injury $(3.34 \pm 0.23,3.34 \pm 0.18$, and $3.31 \pm$ 0.30 at the 1-, 4-, and 24-h time points, respectively, $n=$ 6 for all $)$ was significantly $(P<0.001)$ reduced to levels similar to the nontargeted ${ }^{64} \mathrm{Cu}$-DOTA-comb $(2.82 \pm 0.47$, $2.71 \pm 0.79$, and $3.10 \pm 0.94$ at the 1-, 4-, and 24-h time points, respectively, $P>0.05$ for all 3 time points, $n=6$ for all) (Supplemental Fig. 4A). Additionally, receptor blocking reduced the ${ }^{64} \mathrm{Cu}$-DOTA-CANF-comb uptake ratios to the level of the nontargeted DOTA-comb (1.93 \pm 0.46 vs. $1.76 \pm 0.41,1.87 \pm 0.22$ vs. $1.89 \pm 0.59$, and $1.82 \pm$ 0.55 vs. $1.64 \pm 0.40$ at 1,4 , and $24 \mathrm{~h}$ after injection, $n=$ 6 for all). Furthermore, competitive immunohistochemical blocking resulted in loss of the fluorescent signal for NPR$\mathrm{C}$ in both endothelial and smooth muscle cells (Supplemental Figs. 4B-4E).

\section{DISCUSSION}

We report here the results for PET imaging of NPR-C receptor upregulation associated with ischemia-induced angiogenesis in mice. The presence of the NPR-C receptor was identified with the ${ }^{64} \mathrm{Cu}$-DOTA-CANF-comb nanoprobe and PET/CT, as well as immunohistochemistry. The imaging capability and superiority of the targeted ${ }^{64} \mathrm{Cu}-$ DOTA-CANF-comb nanoprobe over the ${ }^{64} \mathrm{Cu}-\mathrm{DOTA}-$ CANF peptide tracer were demonstrated.

A previous report had indicated the high sensitivity and specificity of ${ }^{64} \mathrm{Cu}$-DOTA-CANF for imaging NPR-C receptors in vivo (17). However, its fast pharmacokinetics resulted in limited sensitivity and contrast in this murine angiogenesis model, thus making a CANF-modified nanoparticle a viable candidate for overcoming these difficulties. In related studies, the poly(methyl methacrylate)-core/ PEG-shell amphophilic nanoparticle showed in vivo behavior that could be accurately tailored by changing the molecular parameters of the starting functionalized copolymer (9). Supplemental Figure 1 is a representation of the synthetic design starting with a mixture of hydrophilic, hydrophobic, and functional monomers, which are copolymerized 


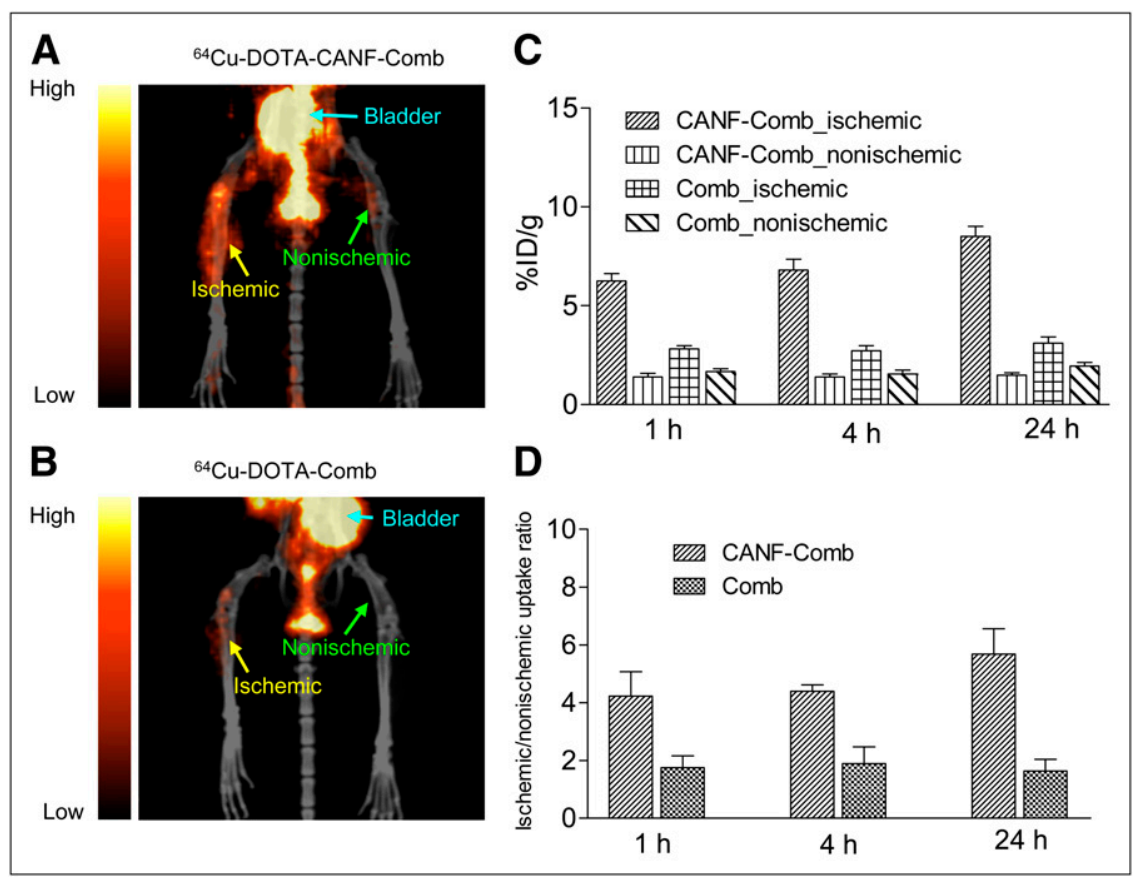

FIGURE 3. PET/CT images of ${ }^{64} \mathrm{Cu}-\mathrm{DOTA}-$ CANF-comb and ${ }^{64} \mathrm{Cu}$-DOTA-comb in HLIinduced angiogenesis model $7 \mathrm{~d}$ after ischemia. (A) ${ }^{64} \mathrm{Cu}-\mathrm{DOTA}-\mathrm{CANF}$-comb in $\mathrm{HLI}$ model showing accumulation of activity in ischemic limb, with little observed in contralateral nonischemic limb. (B) ${ }^{64} \mathrm{Cu}$-DOTAcomb in HLI model showing weak uptake in both ischemic and nonischemic limbs. (C) Uptake of ${ }^{64} \mathrm{Cu}$-DOTA-CANF-comb $(n=8)$ and ${ }^{64} \mathrm{Cu}$-DOTA-comb $(n=7)$. (D) Ischemicto-nonischemic uptake ratios of ${ }^{64} \mathrm{Cu}$-DOTACANF-comb $(n=8)$ and ${ }^{64}$ Cu-DOTA-comb $(n=7)$. to form an amphophilic graft copolymer that, on selfassembly, leads to tailored nanoparticles. The ability to control both the number and the location of functional groups within this nanoscale construct allows a high loading of DOTA macrocycle in the core of the nanoparticle, which in turn results in high specific activity for the ${ }^{64} \mathrm{Cu}$ nanoparticle complexes. In our initial exploration of CANF-modified nanoparticles, we chose to use $5-\mathrm{kDa}$ PEG chains to maximize blood circulation lifetime (18) with the resulting CANF-PEG macromonomer synthesized through click chemistry (Supplemental Fig. 1). Copolymerization with nonfunctionalized PEG macromonomers then gives the desired DOTA-CANF-comb in which $10 \%$ of the PEG chain ends were functionalized with the CANF peptide ( $\sim 14$ per particle) for initial evaluation. Higher loadings of targeting ligand were found to result in significant lowering of blood retention profiles (29).

The biodistribution of the nontargeted control comb showed enhanced blood retention but presumably increased mononuclear phagocytic system uptake (Fig. 1B) compared with the small-molecule ${ }^{64} \mathrm{Cu}$-DOTA-CANF peptide tracer alone (30). Increased accumulation in the ischemic lesion, possibly due to the enhanced permeability and retention effect, (31) was observed, with the increase being modest and consistent with a nontargeted control nanoprobe. After conjugation with the CANF-targeting peptide, the pharmacokinetics of the ${ }^{64} \mathrm{Cu}$-DOTA-CANF-comb nanoprobe were further improved, with decreased mononuclear phagocytic system clearance and extended retention in blood relative to the nontargeted nanoprobe (Figs. 1B and 1C), possibly due to the charge effect of nanoparticles (30). Additionally, the high specific activity $(5.4 \pm 1.2 \mathrm{GBq} / \mathrm{nmol})$ and binding affinity (16) of the ${ }^{64} \mathrm{Cu}-\mathrm{DOTA}-\mathrm{CANF}$-comb required only
7 pmol of tracer for in vivo administration, leading to high contrast and accurate quantification. Thus, ${ }^{64} \mathrm{Cu}$-DOTACANF-comb nanoprobe PET showed significantly enhanced tracer uptake in the injured thigh muscle and improved ischemic-to-nonischemic uptake ratios when compared with the nontargeted nanoprobe during a 24-h study (Figs. 3A-3D). More importantly, compared with the DOTA-CANF peptide tracer alone, uptake of ${ }^{64} \mathrm{Cu}$-DOTA-CANF-comb was 2.2 times higher at $1 \mathrm{~h}$ after injection and increased over time (3.4 at $24 \mathrm{~h}$ after injection) because of the improved blood retention and targeting efficiency and, possibly, the combined enhanced permeability and retention effect. This result clearly demonstrates the importance of multivalency in developing sensitive and specific nanoprobes for molecular PET to improve the targeting efficiency and radiolabeling specific activity.

The HLI model has been used for many studies to identify various biomarkers (27). ${ }^{15} \mathrm{O}-\mathrm{H}_{2} \mathrm{O}$ PET clearly demonstrated the creation of ischemia and restoration of blood flow $7 \mathrm{~d}$ afterward. PECAM staining of the previously ischemic thigh muscle clearly showed a tightly packed bundle of newly formed capillaries, confirmed by hematoxylin and eosin staining (Figs. 4A and 4E), relative to the nonischemic thigh tissue (Figs. 4B and 4F), indicating the presence of angiogenesis. NPR-C staining showed the increased expression of NPR-C receptor and, more importantly, the colocalization with PECAM, confirming the upregulation of NPR-C in the endothelium of neovessels. In addition, the increased expression of NPR-C in smooth muscle cells of previously ischemic tissue, compared with nonischemic tissue, also corroborated NPR-C as a new biomarker for angiogenesis. Competitive receptor blocking with coadministration of an excess of unlabeled CANF peptide/DOTA-CANF-comb nanoparticle 

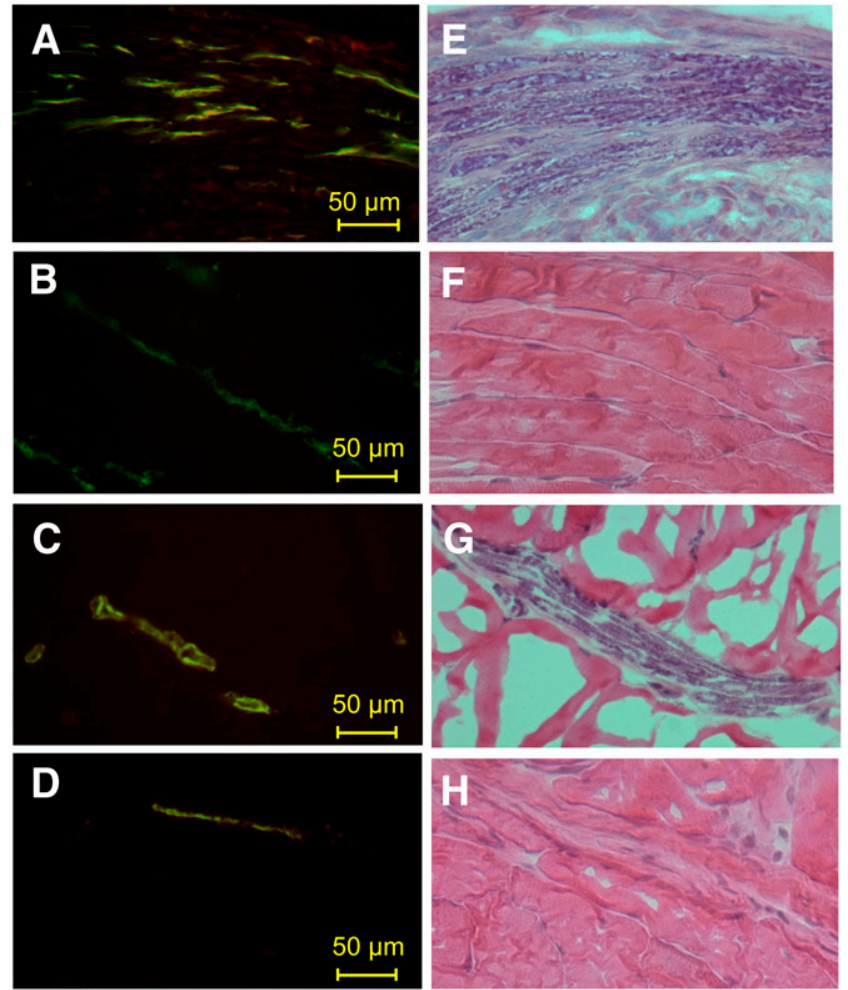

FIGURE 4. Immunofluorescent colocalization of NPR-C with neovessel endothelial cells and vascular smooth muscle cells in previously ischemic thigh muscle collected $7 \mathrm{~d}$ after femoral arterial surgery. (A, C, E, and G) Fluorescent and light images of previously ischemic hind $\operatorname{limb}$ tissue. $(B, D, F$, and $H$ ) Fluorescent and light images of contralateral nonischemic hind limb tissue. Coregistration $(A, C$, and $D)$ (orange) of fluorescent images for PECAM-1 (green) or $\alpha$-actin (green) to NPR-C (red). (E) Hematoxylin and eosin staining showing band of neovessels cut in longitudinal section corresponding to location of fluorescent staining for endothelium and NPR-C in A. (G) Hematoxylin and eosin staining showing coagulation necrosis of muscle and blue-stained nuclei of neovessel (center) and in previously ischemic tissue corresponding to location of fluorescent staining for smooth muscle cell and NPR-C (C). Interestingly, neovessels in previously ischemic tissue and existing capillaries in nonischemic tissue both stained for $\alpha$-actin and NPR-C, although staining was much fainter in nonischemic tissue (D).

decreased the uptake of ${ }^{64} \mathrm{Cu}$-DOTA-CANF $/{ }^{64} \mathrm{Cu}$-DOTACANF-comb tracers in the ischemic limb to a level similar to that obtained in nonischemic control limb, as well as the ischemic-to-nonischemic uptake ratios, indicating NPR-C receptor-mediated tracer uptake. Furthermore, a similar decrease in receptor signal observed in ex vivo immunohistochemistry staining also confirmed the NPR-C specific uptake.

\section{CONCLUSION}

Through modular construction of a DOTA-CANF-comb nanoprobe with tailored physical and biologic properties, we have demonstrated the superiority of a multivalent nanoprobe over the corresponding monovalent, small-molecule CANF peptide for targeting NPR-C receptors in the murine HLI model of angiogenesis. The improved blood retention, high specific activity, elevated targeting efficiency, and enhanced uptake offer this customized amphophilic DOTACANF-comb nanoprobe significant potential for further assessment in other animal cardiovascular disease models, tumor models, and ex vivo human specimens.

\section{DISCLOSURE STATEMENT}

The costs of publication of this article were defrayed in part by the payment of page charges. Therefore, and solely to indicate this fact, this article is hereby marked "advertisement" in accordance with 18 USC section 1734.

\section{ACKNOWLEDGMENTS}

We thank Terry Sharp, Nicole Fettig, Margaret Morris, Amanda Roth, Paul Eisenbies, Lori Strong, Ann Stroncek, and James Kozlowski for their assistance with imaging studies; Susie Grathwohl for technical help with animal surgery and postoperative monitoring; and Tom Voller, Kume Maiko, and Curtis Carey for ${ }^{64} \mathrm{Cu}$ production. This work is supported by the National Heart, Lung and Blood Institute of the National Institutes of Health as a Program of Excellence in Nanotechnology (HHSN268201000046C). The production of ${ }^{64} \mathrm{Cu}$ is supported by the National Cancer Institute (CA86307), and characterization of nanoparticles is performed in the Central Facilities of the UCSB Materials Research Laboratory supported by the MRSEC Program of the National Science Foundation under award DMR 05-20415. No other potential conflict of interest relevant to this article was reported.

\section{REFERENCES}

1. Dobrucki LW, de Muinck ED, Lindner JR, Sinusas AJ. Approaches to multimodality imaging of angiogenesis. J Nucl Med. 2010;51(suppl 1):66S-79S.

2. Gerber HP, Olazoglu E, Grewal IS. Targeting inflammatory cells to improve antiVEGF therapies in oncology. Recent Results Cancer Res. 2010;180:185-200.

3. Wood J, Scott E, Thomas AL. Novel VEGF signalling inhibitors: how helpful are biomarkers in their early development? Expert Opin Investig Drugs. 2009;18: 1701-1714.

4. Almutairi A, Rossin R, Shokeen M, et al. Biodegradable dendritic positronemitting nanoprobes for the noninvasive imaging of angiogenesis. Proc Natl Acad Sci USA. 2009;106:685-690.

5. Wei L, Ye Y, Wadas TJ, et al. ${ }^{64} \mathrm{Cu}$-labeled CB-TE2A and diamsar-conjugated RGD peptide analogs for targeting angiogenesis: comparison of their biological activity. Nucl Med Biol. 2009;36:277-285.

6. Morrison AR, Sinusas AJ. Advances in radionuclide molecular imaging in myocardial biology. J Nucl Cardiol. 2009;17:116-134.

7. Stollman TH, Ruers TJ, Oyen WJ, Boerman OC. New targeted probes for radioimaging of angiogenesis. Methods. 2009;48:188-192.

8. Nune SK, Gunda P, Thallapally PK, Lin YY, Laird Forrest M, Berkland CJ. Nanoparticles for biomedical imaging. Expert Opin Drug Deliv. 2009;6:11751194.

9. Welch MJ, Hawker CJ, Wooley KL. The advantages of nanoparticles for PET. J Nucl Med. 2009;50:1743-1746.

10. Maack T, Suzuki M, Almeida FA, et al. Physiological role of silent receptors of atrial natriuretic factor. Science. 1987;238:675-678.

11. Kong $\mathrm{X}$, Wang $\mathrm{X}, \mathrm{Xu} \mathrm{W}$, et al. Natriuretic peptide receptor $\mathrm{A}$ as a novel anticancer target. Cancer Res. 2008;68:249-256.

12. Pedram A, Razandi M, Levin ER. Natriuretic peptides suppress vascular endothelial cell growth factor signaling to angiogenesis. Endocrinology. 2001;142:15781586.

13. Vesely DL. Atrial natriuretic peptides: anticancer agents. J Investig Med. 2005;53: $360-365$.

14. Brown AP, Citrin DE, Camphausen KA. Clinical biomarkers of angiogenesis inhibition. Cancer Metastasis Rev. 2008;27:415-434. 
15. Murukesh N, Dive C, Jayson GC. Biomarkers of angiogenesis and their role in the development of VEGF inhibitors. Br J Cancer. 2010;102:8-18.

16. Maack T. The broad homeostatic role of natriuretic peptides. Arq Bras Endocrinol Metabol. 2006;50:198-207.

17. Liu Y, Abendschein D, Woodard GE, et al. Molecular imaging of atherosclerotic plaque with ${ }^{64} \mathrm{Cu}$-labeled natriuretic peptide and PET. J Nucl Med. 2010;51: 85-91.

18. Pressly ED, Rossin R, Hagooly A, et al. Structural effects on the biodistribution and positron emission tomography (PET) imaging of well-defined ${ }^{64} \mathrm{Cu}$-labeled nanoparticles comprised of amphiphilic block graft copolymers. Biomacromolecules. 2007;8:3126-3134.

19. McCarthy DW, Shefer RE, Klinkowstein RE, et al. Efficient production of high specific activity ${ }^{64} \mathrm{Cu}$ using a biomedical cyclotron. Nucl Med Biol. 1997;24: $35-43$.

20. Herrero P, Kim J, Sharp TL, et al. Assessment of myocardial blood flow using ${ }^{15} \mathrm{O}$-water and $1-{ }^{11} \mathrm{C}$-acetate in rats with small-animal PET. J Nucl Med. 2006;47:477-485.

21. Malkoch M, Schleicher K, Drockenmuller E, et al. Structurally diverse dendritic libraries: a highly efficient functionalization approach using click chemistry. Macromolecules. 2005;38:3663-3678.

22. Perrier S, Takolpuckdee P. Macromolecular design via reversible additionfragmentation chain transfer (RAFT)/xanthates (MADIX) polymerization. $J$ Polym Sci A Polym Chem. 2005;43:5347-5393.
23. Shokeen M, Pressly ED, Hagooly A, et al. Evaluation of multivalent, functional polymeric nanoparticles for imaging applications. ACS Nano. 2011;5:738-747.

24. Ruotsalainen U, Raitakari M, Nuutila P, et al. Quantitative blood flow measurement of skeletal muscle using oxygen-15-water and PET. J Nucl Med. 1997;38: 314-319.

25. Burchert W, Schellong S, van den Hoff J, Meyer GJ, Alexander K, Hundeshagen H. Oxygen-15-water PET assessment of muscular blood flow in peripheral vascular disease. $J$ Nucl Med. 1997;38:93-98.

26. Liu Y, Ibricevic A, Cohen JA, et al. Impact of hydrogel nanoparticle size and functionalization on in vivo behavior for lung imaging and therapeutics. Mol Pharm. 2009;6:1891-1902.

27. Limbourg A, Korff T, Napp LC, Schaper W, Drexler H, Limbourg FP. Evaluation of postnatal arteriogenesis and angiogenesis in a mouse model of hind-limb ischemia. Nat Protoc. 2009;4:1737-1746.

28. Couffinhal T, Silver M, Zheng LP, Kearney M, Witzenbichler B, Isner JM. Mouse model of angiogenesis. Am J Pathol. 1998;152:1667-1679.

29. Shokeen M, Pressly ED, Hagooly A, et al. Evaluation of multivalent, functional polymeric nanoparticles for imaging applications. ACS Nano. 2011;5:738-747.

30. Owens DE III, Peppas NA. Opsonization, biodistribution, and pharmacokinetics of polymeric nanoparticles. Int J Pharm. 2006;307:93-102.

31. Fang J, Nakamura H, Maeda H. The EPR effect: unique features of tumor blood vessels for drug delivery, factors involved, and limitations and augmentation of the effect. Adv Drug Deliv Rev. 2011;63:136-151. 